\title{
SOBRE A CONCEPTUALIZAÇÃO CONTEMPORÂNEA DO “ESPAÇO” NA CULTURA OCIDENTAL
}

\author{
Henrique Garcia Pereira ${ }^{1}$
}

\begin{abstract}
Resumo - Este texto discute a categoria filosófica de "espaço", atendendo à sua importância crescente na cultura ocidental. Estuda-se o impacto dessa categoria em diferentes ciências (para além da geografia) e sublinha-se o seu importante significado simbólico na literatura e nas artes (evocando o exemplo dos Rовотs-PINTOREs). Como interacção entre o espaço urbano e a mente humana afectiva, apresenta-se o caso da deambulação surrealista e da psicogeografia dos situacionistas. Finalmente, salientam-se as modificações sofridas pelo espaço físico e virtual, em termos do seu tempo de atravessamento através das tecnologias físicas e computadorizadas.
\end{abstract}

Palavras chave: Viragem espacial, acontecimento, psicogeografia, Rовотs-PINTORES, surrealismo.

Abstract - ON THE CONTEMPORARY CONCEPTUALIZATION OF 'SPACE' IN WESTERN CULTURE. This paper discusses the philosophical category of 'space', given its growing importance in Western culture. It explores the impact of this category in different sciences (beyond geography) and underlines its significant symbolic meaning in literature and the arts (evoking the PAINTING-ROBOTS example). Surrealistic flânerie and situationistic psychogeography are addressed as an interaction of urban space with the affective human mind. Finally, the paper focuses on the reordering of physical and virtual space in terms of its interaction with time, as a consequence of physical and computer-generated technologies.

Keywords: Spatial turn, event, psychogeography, painting-robots, surrealism.

\section{INTRODUÇÃO}

Não se pode analisar sob o prisma exclusivo do tempo (e sua aceleração descontrolada) o processo de modernização (e pós-modernização) cultural que caracteriza a cultura oci-

Recebido: Fevereiro 2015. Aceite: Abril 2015.

1 Henrique Garcia Pereira é Professor catedrático do Instituto Superior Técnico, tendo como interesses principais a estatística e a epistemologia. Para além de uma centena de artigos em revistas de toda a índole, escreveu alguns livros, de que se destacam "Brasiliana Tangencial" (IST Press) e "Fragmentos do Mediterrânio" (Teorema, três volumes). E-mail: henrique.pereira@tecnico.ul.pt 
dental contemporânea, já que as transformações conceptuais referentes ao "espaço" se vão tornando hegemónicas nos dias de hoje (e de maior complexidade, visto que o tempo é unidimensional e tem um sentido único, enquanto o espaço é - pelo menos - 3D, e cada uma das suas dimensões pode desenvolver-se em qualquer direcção e sentido).

Parece que é necessário conceber os dois conceitos - tempo e espaço - em pé de igualdade, como era convicção de Kant e Bergson. Mas "pé de igualdade" em termos valorativos não quer dizer obviamente equivalência em termos formais, como sustenta Hartmut Rosa, comummente considerado "filósofo do tempo". Em Rosa (2011) - o seu importante texto que, aliás, é um libelo crítico contra a aceleração da vida contemporânea - afirma-se que a "data de nascimento" da modernidade coincide com a emancipação do tempo (o que implica a sua menoridade anterior). Essa emancipação do tempo relativamente ao lugar só foi possível a partir da invenção do relógio mecânico (Rosa, 2011: 45). Na sequência dessa invenção, a cultura ocidental passou a concentrar-se mais no tempo, face a um anterior primado antropológico do espaço, antes da Revolução Industrial.

Mas esta tendência em sobrevalorizar o tempo parece inverter-se nos nossos dias com a pregnância conceptual do espaço, em todas as suas facetas. Essa pregnância exprime-se por uma ontologia caótica (radicalmente diferente de época para época), ligada ao fenómeno da multiplicidade das identidades, em que cada instância identitária é situada num certo contexto espacial, destruindo a experiência secular da identidade única ("para a vida", e por vezes para além dela, como no caso dos "heróis e santos").

\section{O ESPAÇO COMO CATEGORIA FILOSÓFICA HEGEMÓNICA NOS NOSSOS DIAS: “THE SPATIAL TURN” E SEUS ASPETOS SOCIOLÓGICOS E POLÍTICOS}

A partir da "revolução científica" do século XVII, a filosofia ocidental do mainstream - cujos novos contornos assinalavam a passagem do capitalismo comercial e mercantil para o industrial - tomava o espaço como algo de homogéneo e isótropo, uma abstracção que poderia ser vista como uma espécie de background liso onde se colocam os objectos cujas relações (métricas) se pretendiam quantificar segundo modelos baseados, em especial, na simples Geometria à la Pitágoras, ou na mecânica newtoniana, assente na primeira e na viragem coperniciana.

Com o desenvolvimento da topologia (de Euler a Poincaré), o conceito de espaço passou a abarcar questões qualitativas novas como a vizinhança, a inclusão, a relação, excluindo (ou minimizando) o recurso à distância euclidiana para expressar as relações espaciais entre objectos, que se baseiam - desde o célebre problema das pontes de Könisberg, resolvido por Euler - no conceito de rede, expresso matematicamente na "teoria dos grafos" (Biggs et al., 1986). Surge assim um novo conceito de espaço discreto, consistindo apenas de nós e ligações, em que o background fica indeterminado. Assim, as geometrias não-euclidianas (por exemplo o approach geométrico de Riemann que liberta as coordenadas de todo o sentido métrico), e a teoria da relatividade (em que a métrica é uma propriedade da matéria que não pode ser imposta a priori) - significativamente coevas tanto da segunda revolução industrial 
(baseada no petróleo e na electricidade) como das vanguardas artísticas do princípio do século XX - tiveram o seu papel no "nivelamento" da importância filosófica das duas categorias (o tempo e o espaço), que acabavam por se constituir num espaço-tempo contínuo. Aliás, essas duas categorias tiveram um claro tratamento conceptual por parte de Minkowsky, que afirmava (em 1905): "Ninguém observou, ainda, nenhum lugar excepto num tempo, nem ninguém observou nenhum tempo excepto num lugar (citado em Gray, 1992: 255).

Em meados do século XX, com o trabalho de Lefebvre (1970) dedicado principalmente à reflexão sobre o urbanismo, o espaço torna-se uma categoria filosófica extremamente fértil, impondo-se ao próprio "tempo" (essa quintessência da filosofia ocidental desde Heráclito) pelos defensores do spatial turn ( $v d$., por exemplo, Pickles, 2004). De facto, Lefebvre defende que o espaço - onde se insere o fenómeno urbano que se tornou dominante no século XX - deve ser concebido como uma forma particular de interacção entre a geografia e o homem, exprimindo a especificidade da cidade, como "obra", a qual é "mais aproximável da obra de arte do que um simples produto material", nas próprias palavras de Lefebvre (2012: 56). Esta obra é revelada em especial de noite, vista de avião (como se ilustra na figura 1) e, para este sistema semiótico, a distância euclidiana "não funciona", sendo necessário definir uma nova distância (denominada significativamente "distância de Manhattan"), em que o caminho mais curto entre dois pontos não é a recta, mas uma linha quebrada que segue o rumo imposto pela rede de artérias da cidade. In addition, numa deslocação física por uma malha urbana, podem surgir fenómenos de impossibilidade, como por exemplo os culs de sac (fenómenos que não podem obviamente ocorrer nos espaços desterritorializados, onde a distância euclidiana "salta todos os obstáculos").

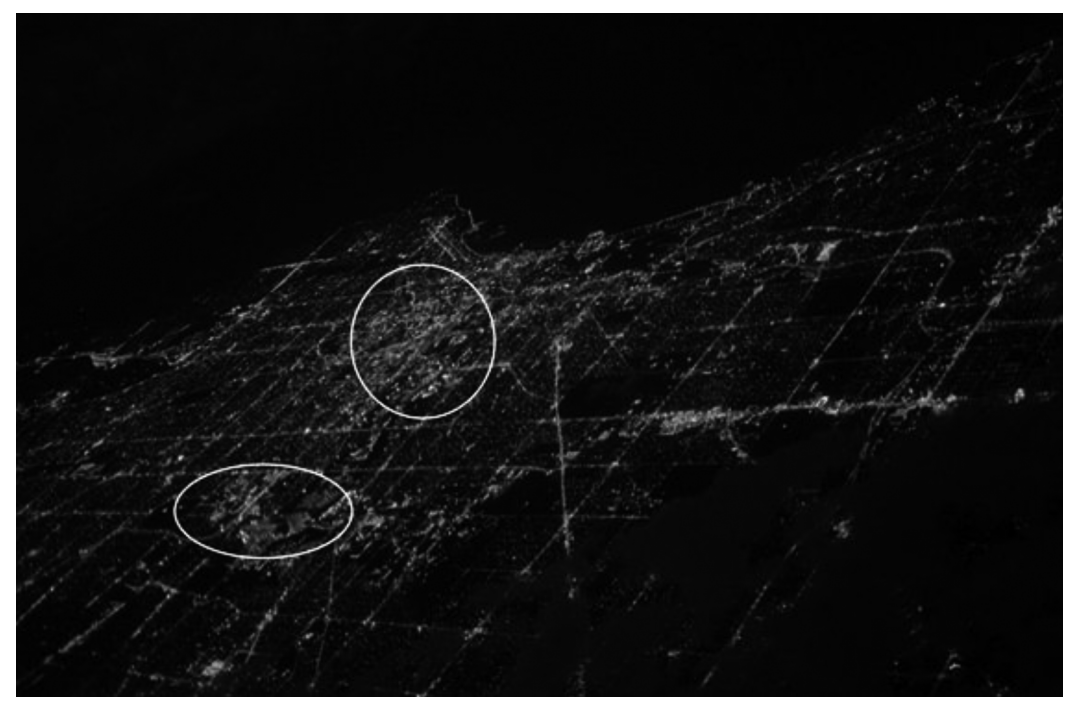

Fonte/source: composição do autor sobre imagem do Google Earth

Fig. 1 - O espaço urbano à la Lefebvre, com dois núcleos primários.

Fig. 1 - Lefebvre's Urban Space, with two initial nuclei. 
Quando se vê a forma urbana "de cima", reconhece-se em geral uma distribuição populacional organizada em torno de um (ou mais) núcleo(s) primário(s). Mas essa vista "de cima" é também a do Estado, reificada num mapa bidimensional, como se desenvolve seguidamente, nos seus aspectos ligados à sociologia urbana.

De modo mais geral, e aproximando-nos do cerne da filosofia ocidental do século passado (em que Lefebvre questiona a sociedade do nosso tempo a partir da sua componente mais visível: o "espaço", transfigurado em mercadoria pelo capitalismo e sujeito às regras do mercado), poderemos sintetizar a contribuição do pensador francês neste domínio dizendo que a característica mais relevante do espaço é o facto de ter sido produzido pelo homem em sintonia com o seu desenvolvimento social cada vez mais complexo, o que implica que a cidade não é (só) o "cenário" onde se desenvolve a produção ou concentração de capitais. De facto, o papel mais importante do urbano é o modo como intervém na própria articulação dos meios de produção. Na verdade, Lefebvre - ao adaptar o pensamento de Marx às condições objectivas da segunda metade do século passado, inserindo dialecticamente o espaço na economia política - deduziu que a organização do espaço revela as relações conflituantes da sociedade que ocupa esse espaço (por exemplo, o détachement extremamente claro e veemente entre os bairros operários e as zonas da cidade ocupadas pela burguesia, nos tempos da revolução industrial). E o que é mais interessante é que esta ruptura entre espaços pode ser revelada precisamente pela ocultação de um deles (sempre, o mais "desvalorizado"), como nos conta Engels na sua célebre boutade sobre a "sua" Manchester natal, quando se deu conta de que os "seus" operários (que atulhavam, durante as horas de trabalho, as "suas" fábricas) desapareciam da cidade durante a noite. Essa constatação transformou-o talvez no primeiro sociólogo urbano, ao investigar o modo como a "sua" burguesia organizava o espaço da cidade de modo a que qualquer "viajante incauto" que percorresse Manchester de uma ponta a outra "fosse poupado" à própria existência visível dos degradados bairros operários, eficazmente segregados do espaço urbano da cidade. De uma perspectiva dialéctica, focada na influência das formas urbanas no modo de funcionar da sociedade (em que os termos permutam relativamente ao caso anterior relatado por Engels), e abarcando contextos latino-americanos mais simples do que os emaranhados palimpsestos da maioria das cidades europeias, podemos pensar que são as estruturas existentes no espaço que condicionam (até um certo ponto) as formas de organização da sociedade, como exemplifica Santos (2007), num significativo exemplo em que a dialéctica lefebvriana é vista no sentido cidade $\rightarrow$ sociedade (Santos, 1997). O tecido urbano pode assim ser descrito como um ecossistema, como unidade coerente que produz relações sociais específicas. A partir dos finais do século XIX, o proletariado - expulso para uma suburbanização forçada pela revolução industrial - perdeu a criatividade que a hibridez do centro da cidade tendia a fomentar, e que se manifestava em "obras" (não em produtos). Assim a realidade urbana é considerada como a projecção da sociedade sobre o terreno, dando origem a um conjunto de signos, em que os monumentos e as festas desempenharam um papel crucial (Lefebvre, 2012: 65).

Mas foi talvez Gilles Deleuze quem deu a contribuição mais expressiva para o spatial turn que bifurcou o pensamento filosófico contemporâneo (Deleuze e Guattari, 
1980), levando a um novo framework teórico que deu origem a uma clarificação (e enriquecimento) no domínio da epistemologia da geografia, abrindo assim uma zona de interface onde floresce a colaboração geógrafos vs. filósofos. De resto, Deleuze declinou o espaço em todas as suas formas, da linha de fuga aos espaços lisos/estriados (Deleuze e Parnet, 1996).

Segundo Deleuze, em vez de analisar os acontecimentos como parte de um contínuo passado/presente, deveríamos analisá-los como fragmentos limitados e distorcidos de um futuro utópico, que está inactivo no presente (parecendo oculto), mas que é potencialmente explosivo.

Pode talvez sintetizar-se prosaicamente este conjunto de ideias através das linhas de abertura do prefácio de Kaplan (2012): A good place to understand the present, and ask questions about the future, is on the ground, travelling as slow as possible.

\section{O CONCEITO CONTEMPORÂNEO DE ESPAÇO}

Nos primórdios do século XXI e no contexto da "crise" financeira do capitalismo globalizado, surgiu um approach teórico inspirado no movimento Occupy e na vaga de revoltas que varreu o mundo em 2011-2015, baseado no espaço urbano de uma miríade de países, e centrado nas "praças" centrais das principais cidades desses países (da Puerta del Sol a Wall Street, de Tahrir a Syntagma). Esse approach original, do qual Gordillo (2012) pode ser considerado o representante mais inovador, assenta numa versão não-trivial de "terreno" como reelaboração do antigo conceito de "lugar", atendendo à "pulsação" afectiva característica dos diferentes tipos de ocupação subversiva do espaço físico das praças, recombinando esse espaço com o tempo (a forma material do "terreno" fica dotada de uma temporalidade que transforma o próprio espaço). Esta nova versão do conceito de "terreno" assenta em alguns factos empíricos que permitem uma certa reformulação de determinados aspectos da geografia "clássica": por exemplo, sabe-se que, no Gran Chaco sul-americano, ao chegar a estação das chuvas, uma região plana e semiárida se transforma subitamente num vasto pântano intransponível; na Rússia, a chegada do inverno altera significativamente a forma do terreno pelo surgimento de sólidos blocos de neve que restringem seriamente (como no caso anterior) a mobilidade humana. Fazendo uma ponte simbólica entre estes casos da interface homem-natureza e o movimento das ocupações das praças, Gordillo (2012: 40), chamou a atenção para o facto de a tempestade de neve que assolou Wall Street no fim de Outubro de 2011 ter alterado profundamente o "estilo" de vida dos ocupantes: por exemplo, quando a polícia confiscou os caloríferos dependentes de fontes energéticas externas, foi necessário encontrar meios autónomos de aquecimento, em particular a geração de energia à custa de geradores accionados por "indignados-ciclistas" que pedalavam num sítio fixo, à maneira dos guerrilheiros da guerra do Vietname.

Obviamente ligado aos movimentos não violentos de contestação (do poder financeiro mundial) atrás referidos, que têm surgido com intensa pregnância nos países mais desenvolvidos (como queria Marx), emergiu - na segunda década do nosso século - uma 
conceptualização profundamente original do espaço, ancorada no pensamento de Slavoj Žižek, um dos mais interessantes intelectuais dos nossos dias. Essa conceptualização baseia-se na ideia de Event, which is an amphibious notion with even more than fifty shades of grey that appears to happen all of sudden, without discernible causes, and interrupts the usual flow of things (Žižek, 2014: 1-2). Ao conteúdo do acontecimento ligado à política contestatária, adiciona-se uma miríade de outros significados com fronteiras fuzzy, como a questão crucial do amor, que partilha com as outras acepções uma circularidade constitutiva, em que o efeito do acontecimento determina retroactivamente as suas causas e razões, num poderoso feed-back positivo. Afirma Žižek (2014: 2): I do not fall in love for precise reasons (her lips, her smile...) - it is because I already love her that their lips, etc., attract me. Na conceptualização genérica do filósofo esloveno, o acontecimento é um efeito que parece exceder as suas causas, e o ESPAÇO do acontecimento é aquilo que abre o gap que separa o efeito das causas. Há uma separação espacial decorrente da COMPLEXIDADE multidimensional das ligações entre os seres e os objectos em redes profundamente enoveladas que não tem nada a ver com os lags que podem ocorrer em séries temporais, as quais - por construção - dependem só do parâmetro cronológico, obviamente unidimensional. Com esta (aparentemente) "banal" sobrevalorização conceptual do espaço em relação ao tempo, encontramo-nos - por via da causalidade - no crux da filosofia ocidental (Žižek, 2014: 4), ao problematizar a questão da generalidade dos links causais, assim expressa pelo pensador heterodoxo: Does everything that exists have to be grounded in sufficient reasons? Or are there things that somehow happen out of nowhere? (Žižek, 2014: 4). Estes dois approaches parecem ter dominado de um modo mutuamente exclusivo a filosofia ocidental desde os seus primórdios, e designam-se, respectivamente, por "transcendental" (corporizado em Heidegger), e "ontológico", accaparé quase em exclusivo pelas hard sciences, e protagonizado hegemonicamente por Stephen Hawking. O que é espantoso (Žižek, 2014: 6) é que ambos os approaches venham a culminar em alguma noção de event: para Heidegger, o horizonte de conhecimento é que determina o modo como aprendemos a realidade e nos relacionamos com ela; para a concepção de um acontecimento primordial representada por Hawking (e outros, na mesma linha de pensamento), domina a ideia do Big Bang. E voltamos assim à questão da "multiplicidade inconsistente" atrás esboçada a propósito do AMOR, com a emergência surpreendente de algo novo que prevalece em qualquer esquema estável, e a que Hegel chamava "universalidade concreta", uma universalidade que não é só um receptáculo do seu conteúdo particular, mas que engendra esse conteúdo através dos seus imanentes antagonismos e deadlocks. É fácil de ver que não estamos a falar de outra coisa do que do ESPAÇO.

\section{O ESPAÇO EM ALGUMAS DISCIPLINAS AFINS DA GEOGRAFIA (E EM OUTROS RAMOS DA CULTURA)}

Para que a categoria "espaço" atrás esboçada seja útil no pensamento reflexivo em disciplinas (ou áreas do conhecimento) afins (ou conexas) da (com) a geografia, como 
por exemplo a arqueologia, a geologia, a antropologia social, ..., é necessário trabalhar em conjunto nos dois domínios, postulando também alguns pressupostos básicos.

No que diz respeito à arqueologia, o mais importante desses pressupostos consiste em admitir que o spatial patterning dos artefactos arqueológicos (cerâmica, vestígios de construções, armas, utensílios metálicos...) encontrados hoje reflecte de algum modo o padrão espacial de actividades desenvolvidas no passado, e que esse padrão espacial (expresso por relações de proximidade, contiguidade territorial ou de clustering) teve um papel significativo na interacção humana. É no entanto crucial relativizar esse papel: o factor espacial é de facto significativo, mas só se estiver integrado num contexto construído a partir de uma miríade de outros factores (históricos, etnográficos, ecológicos, linguísticos, ...) que podem influenciar a estrutura cultural das comunidades examinadas pelo trabalho arqueológico. Assim, as correlações entre groupings arqueológicos e históricos têm de ser analisadas criticamente, para descartar a eventualidade (frequente) de associações espúrias decorrentes do facto óbvio de que as fronteiras entre unidades culturais são extremamente difusas e dinâmicas, não podendo, consequentemente, de modo nenhum serem "estabelecidas" exclusivamente a partir da similitude entre assemblagens espaciais. Apesar deste argumento (e desde que a interdisciplinaridade e o approach sistémico funcionem de facto na prática científica), existe efetivamente uma correspondência estocástica com valor heurístico entre the archeological evidence for influence and change, and historical events, como se demostra convincentemente no trabalho pioneiro de Hodder (1978).

No que diz respeito à geologia, não há dúvida de que o seu estatuto epistemológico foi subvalorizado nos primeiros dias da Revolução Industrial, embora - paradoxalmente - fosse o corpo de conhecimentos que trouxe à luz do dia (metafórica e espacialmente) o carvão e o ferro que alimentavam e constituíam as máquinas que determinaram tal período crítico da história humana (este aspecto pode talvez ligar-se à circunstância de a Revolução Industrial ter sido conduzida primordialmente por "empreendedores" e não por cientistas, pelo menos no seu arranque). Só quando o "ambiente" entrou nas preocupações filosóficas de alguma cultura ocidental, no terceiro quartel do século XX, é que a geologia - como ciência onde assentam (teórica e fisicamente) as questões e as configurações do solo e da água - foi pensada filosoficamente como raiz de toda a actividade económica baseada nos recursos naturais (o tipo de milho depende da terra onde é plantado e mesmo os chips são feitos de silício!). A geologia ganhou então um "estatuto" mais expressivo, baseando-se no pressuposto do UNIFORMITARISMO (proposto já por Lyell no século XIX, mas cedo descurado pelo mainstream científico-filosófico, dominado pela física). O uniformitARISMO consiste em admitir que os processos que se deram no passado (e que são o objecto da geologia) são análogos aos que se dão hoje, fechando a porta a algumas bifurcações do tipo catastrófico (à la Thom), e promovendo uma hermenêutica baseada num "trabalho de campo" em que não intervem a geometria euclidiana senão para a cartografia baseada no GPS e no GIS (e num trabalho de laboratório a-histórico).

No que diz respeito à antropologia social aplicada aos movimentos subversivos que levaram à ocupação transgressiva do espaço público, Gordillo (2012: 34) afirma que 
esta forma espacial de protesto parece única (e original) na história ocidental, mostrando um pulsar inédito de nós que constituem as articulações locais de uma rede anticapitalista sem leaders. Cria-se assim uma topologia política que funciona como uma caixa de ressonância cuja temporalidade não é linear nem previsível (assumindo-se como uma configuração "caótica", no sentido científico de um sistema dinâmico não-linear).

Se nos desviarmos um pouco mais das data driven sciences, e nos debruçarmos sobre outros ramos da cultura (que manipulam, em especial, símbolos, como a literatura e as artes), a categoria "espaço" pode surgir sob uma forma obviamente diferente (ligada, por exemplo à noção de "lugar" e de "não-lugar") como se sugere ironicamente na figura 2 , no que diz respeito à escrileitura do urbano...

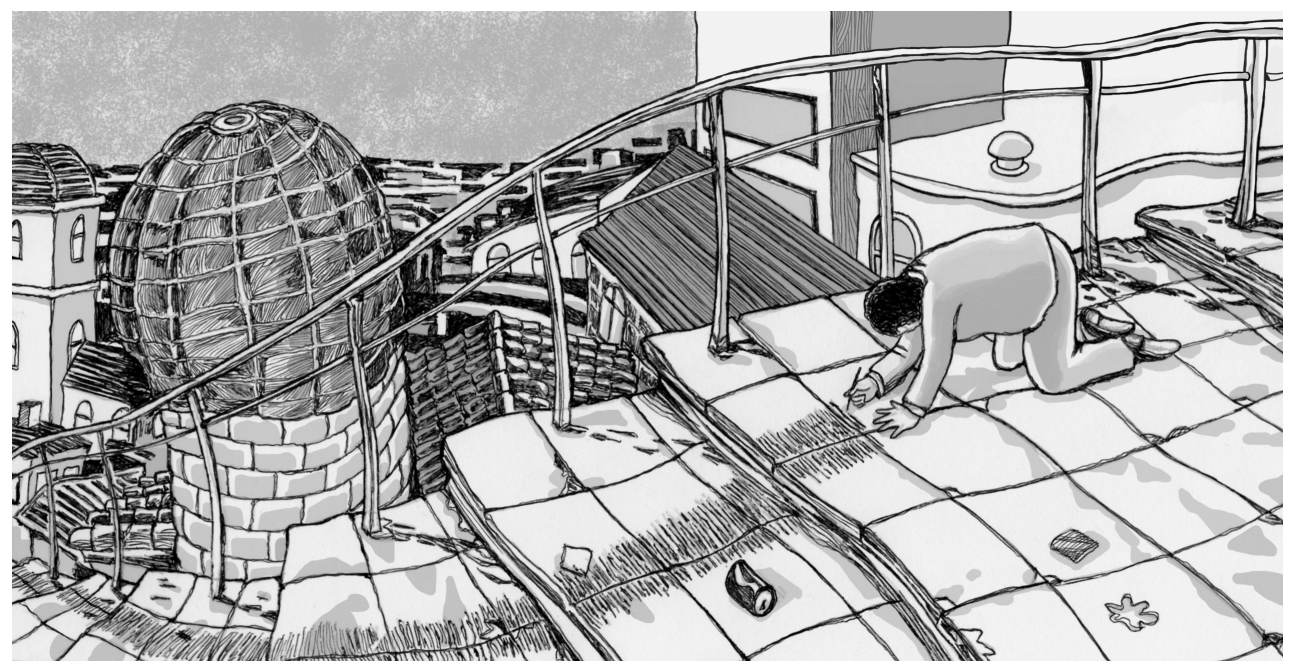

Fonte/Source: Chico, 2014: 12

Fig. 2 - A Geografia escrita.

Fig. 2 - Written Geography.

Desenvolvendo agora um pouco as relações entre a literatura e a geografia, não podemos deixar de pensar na Lisboa de Pessoa, na Dublin de Joyce, na Buenos Aires de Borges, na Trieste de Svevo (e de Magris, que depois abriu para o "Danúbio", um dos livros mais preciosos da geografia literária). Quanto à "geografia mítica", esta elevou-se ao seu máximo expoente com as "Cidades Invisíveis" de Italo Calvino.

Mas o que é (aparentemente) mais insólito é que, quando Robert Louis Stevenson resolveu converter o seu Dr. Jekyll numa personagem dupla e o transforma em Mr. Hyde, o plumitivo escocês não se limita a fazer variar a fisionomia e o temperamento da sua personagem, mas modifica também o seu lugar de residência, já que, como diz Chico (2014), Hyde "não pode viver na mesma casa do seu alter ego". 
Fica assim espelhada na escrileitura a relação da palavra com o sítio, para além (i.e., noutra configuração) do locus amoenus da poesia bucólica, arrumada nos palácios montanhosos do romantismo (e nas villas campestres de Ovídio). E não há dúvida de que a Weltanschauung de cada um de nós é algo que determina o (e é determinada pelo) lugar onde habitamos. Quanto aos viajantes nómadas, que não habitam em qualquer lugar como Chatwin, a sua filosofia é precisamente o nomadismo físico ou intelectual. A história da literatura pode assim ser vista como uma sequência de lugares que se sucedem indefinidamente, mostrando (e representando) não só um Zeitgeist, mas - especialmente - um Raumgeist.

\section{A PSICOGEOGRAFIA A DIFERENTES ESCALAS}

Para além dos aspectos ligados às ciências e à literatura, o "espaço" (ou a passagem por espaços diferentes), pode provocar na psique dos homens (em certos casos) um efeito não despiciendo: quantas vezes o mood dos indivíduos é afectado - e modificado - pela sua passagem por paisagens espaciais diferentes, tanto urbanas como rurais.

Num contexto urbano ligado à modernidade, este aspecto da interacção do espaço com a mente emocional foi desenvolvido extensamente por Baudelaire e Walter Benjamin na viragem do século XIX (e princípios do século XX), dando origem ao arquétipo do "flâneur", aquele que deambula pela cidade sem objectivo bem definido, para além de "passear" ao sabor das suas "inclinações" psíquicas e caprichos emocionais (que se vão também modificando com a transição dos espaços).

O movimento surrealista - quer nas várias vertentes dos seus conteúdos diferenciados em diferentes países, quer nas escolas de pensamento, das quais a mais conhecida é a de Breton, de uma legendária ortodoxia - teve um papel crucial na conexão atrás referida entre o espaço e os sentimentos: basta lembrarmo-nos dos exemplos paradigmáticos de «Nadja» (Breton), e de «Le paysan de Paris» de Aragon (fig. 3).

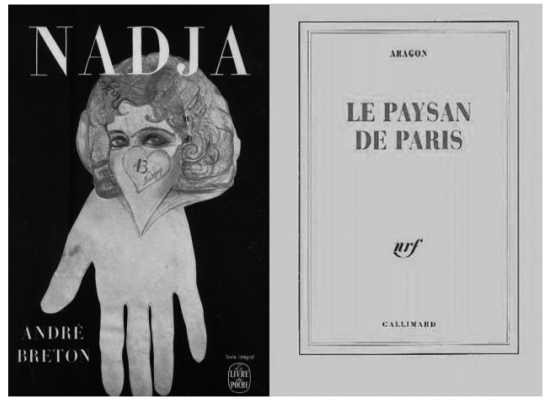

Fig. 3 - Dois livros importantes do surrealismo francês em que o espaço interage com os sentimentos das personagens.

Fig. 3 - Two important books from French surrealism in which space interacts with the characters' feelings. 
No domínio das "artes plásticas", os surrealistas desenvolveram uma forma inédita de interacção de um grupo de artistas entre si, e com o espaço (neste caso, o espaço da tela). Trata-se de um processo artístico que produz um "cadavre exquis" (por exemplo a pintura representada na figura 4), resultante da seguinte sequência:

O primeiro artista toma o espaço de um canto da tela e pinta aí o que lhe apetecer.

Depois de escondido cerca de $2 / 3$ do espaço da tela onde se situa a obra do primeiro artista, o segundo artista analisa a zona que ficou a descoberto (o restante $1 / 3$, fracção que pode variar entre largos limites, como seria de esperar num procedimento surrealista).

A partir dessa análise, prolonga no espaço da tela a obra do primeiro artista com a sua própria contribuição, a qual deve ter (surrealisticamente) uma ligação qualquer com a obra do primeiro artista.

O processo continua nos mesmos moldes, segundo a regra de que cada artista nunca tem acesso à Gestalt da obra, mas apenas a uma pequena fracção, que lhe serve de "semente" para a sua própria contribuição (aquilo que ele acrescenta, segundo o espaço disponível, ao que foi pintado pelos artistas que o precederam).

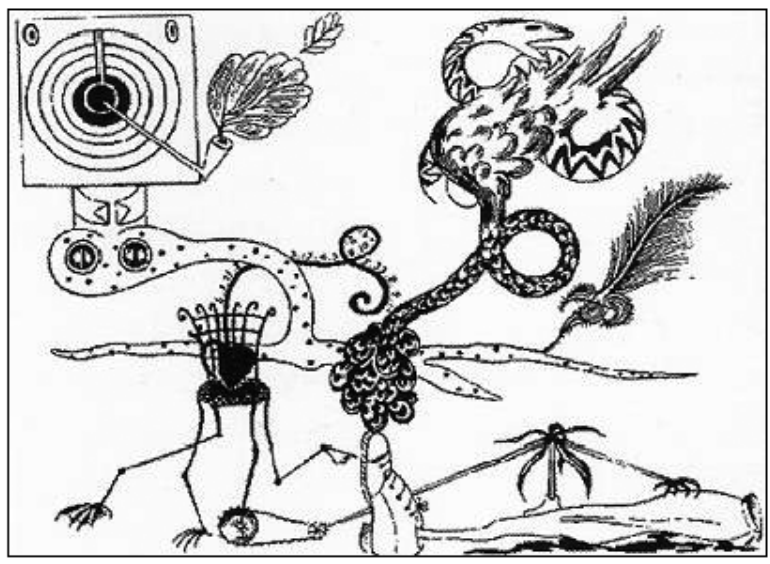

Fonte/source: Moura \& Pereira, 2004

Fig. 4 - Cadavre exquis (Tzara, Hugo, Knutzen, Breton).

Fig. 4 - Exquisite corpse (Tzara, Hugo, Knutzen, Breton).

Em Moura e Pereira (2004), um procedimento homólogo, mas baseado em grandezas mensuráveis (como a intensidade da cor) foi desenvolvido no âmbito de um projecto designado por вовотs-PINTORES, cujo objectivo era criar artworks por um colectivo autónomo de um swarm de robots. Nesse projecto, após uma inicialização aleatória, cada robot só "vê" (através dos seus sensores de cor) aquilo que os precedentes fizeram, e é dirigido através de um estímulo para as zonas do terrarium (o espaço subjacente aos robots enquanto pintam, $v d$. figura 5) já visitadas pelos anteriores agentes. $\mathrm{O}$ estimulo traduz-se por um "apelo" maior (expresso por um feed-back positivo programado no chip 
do robot), o que leva a padrões diferenciados. A obra final é constituída pelos traços deixados na tela que cobre o terrarium, os quais têm uma gama de intensidade de cor mais visível nas regiões "mais frequentadas".

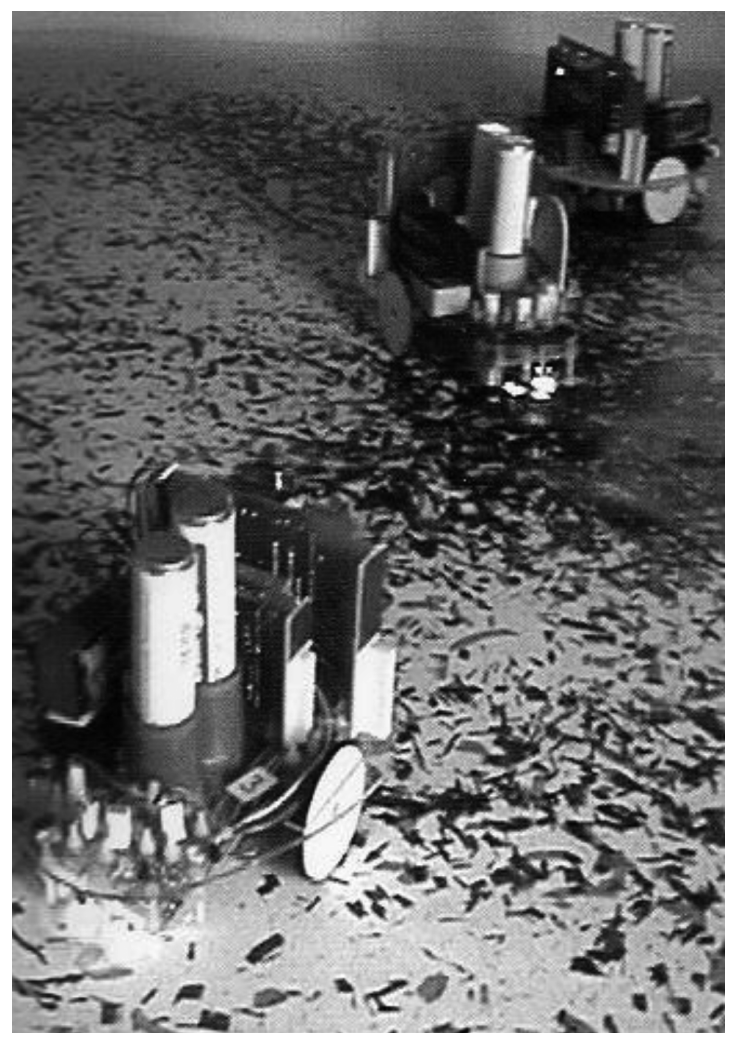

Fonte/source: Moura \& Pereira, 2004

Fig. 5 - A digressão espacial dos Rовотs-PINTORES sobre a tela durante o processo criativo.

Fig. 5 - The spatial digression of the PAINTING ROBOTS on canvas during the creative process.

As diferenças em relação ao cadavre exquis é que cada robot está programado para responder autonomamente (e bottom up) aos seus predecessores, enquanto os agentes humanos retomam o trabalho dos anteriores a seu bel-prazer (mas a programação dos robots e a sua interacção no espaço do terrarium conduz a trajectórias espaciais de tal modo flexíveis que não podem sair dois outputs iguais...).

Passando à escala da cidade, a deriva psicogeográfica - extensão da flânerie a grupos em interaç̧ão que registavam as diferentes experiências induzidas pela diferenciação do espaço urbano durante passeios a pé semi-planeados - foi intensamente exercitada em 
meados do século passado por um grupo artístico-político de raiz francesa, designado por "Internationale Situationniste" (Vários, 1958). Após estudarem os percursos de uma estudante vivendo no XVI ${ }^{\text {ème }}$ (fig. 6), imaginaram um procedimento de deslocação a pé pela cidade que pudesse trazer alguma poesia à vida quotidiana, em oposição aos itinerários obrigatórios da grande maioria dos habitantes de Paris (e de outras cidades). Estes experimentos deram origem a novos conceitos de interacção com a paisagem que, no nosso século, se podem designar por Walkscapes (Careri, 2002).

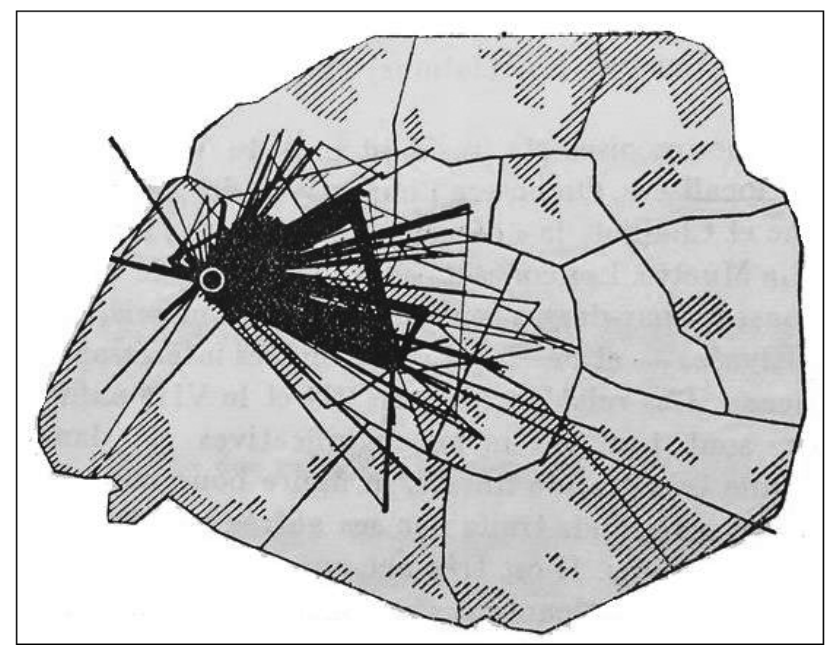

Fonte/Source: Vários, 1958, In C.de Lauwe,"Paris et l'agglomération parisienne”, PUF

Fig. 6 - Deslocações anuais de uma estudante vivendo no $16^{\circ}$ bairro em Paris.

Fig. 6-Annual movements of a student living in the $16^{\circ}$ district in Paris.

Voltando aos surrealistas, agora no que diz respeito à cartografia imaginária à escala do Globo, analisemos a figura 7, que é uma distorção obviamente intencional do espaço, onde as anamorfoses nos dois sentidos (dilatação espacial da Rússia e do Alasca, desaparecimento da Ibéria e da Grécia) se fazem por vontade subjectiva dos "cartógrafos" que atribuíram uma área diferenciada a cada território em função do seu interesse emocional pelo espaço confinado por esse território. Por exemplo, no caso do desvanecimento da Grécia, é bem conhecida a sanha dos surrealistas contra os Gregos antigos, considerados "responsáveis" por todos e quaisquer males de que padece a civilização ocidental, cujas raízes na Ática eram indiscutíveis: o que faziam os surrealistas era afirmar aos quatro ventos (e de um modo bombástico, como lhes era próprio) que todo e qualquer "defeito" que encontravam no pensamento hegemónico a Ocidente resultava da "filosofia grega" iniciada - e quase terminada... - no século $\mathrm{V}$ a.C. 


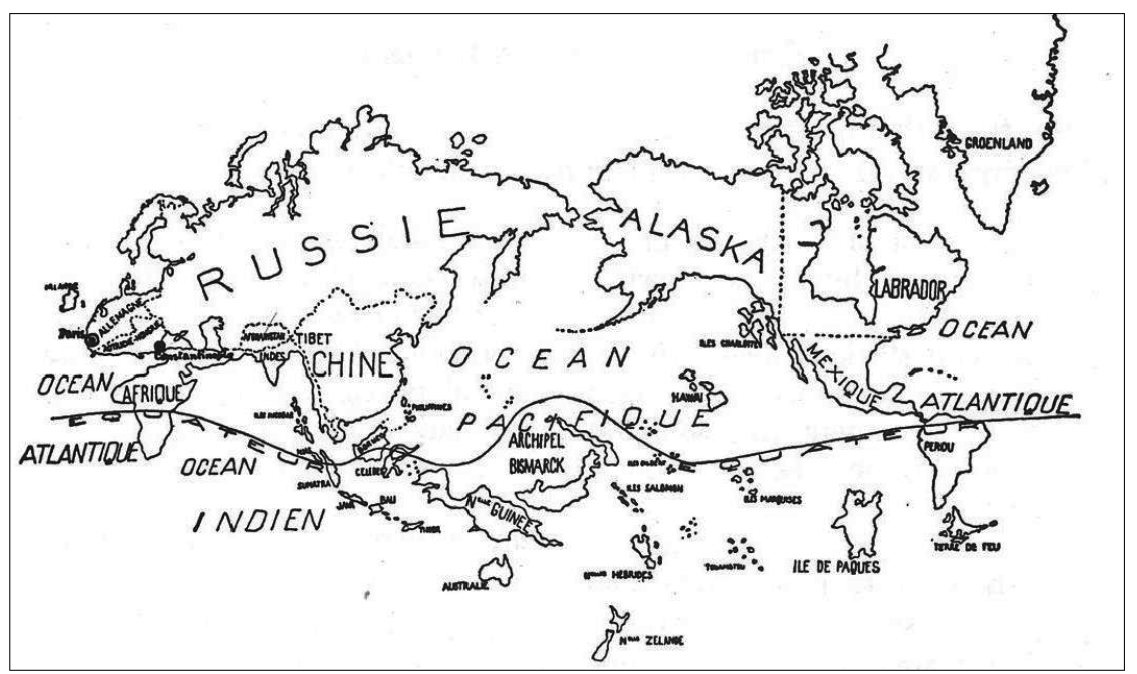

Fonte/source: Variétés, juin 1929, in Diego, 2008.

Fig. 7 - O mapa mundo segundo os surrealistas franceses.

Fig. 7 - The World map according to the French Surrealist Group.

\section{O ATRAVESSAMENTO RÁPIDO DO ESPAÇO (E SUAS POSSÍVEIS CONSEQUÊNCIAS)}

Tentando tornar o espaço cada vez mais transponível em tempos cada vez mais curtos, o homem foi inventando meios de transporte cada vez mais rápidos, chegando - em termos quotidianos generalizáveis à maioria - ao avião, que veio "substituir" o sonho das pontes transatlânticas, imaginadas pelo nosso Repórter X (Reinaldo Ferreira). Com o transporte aéreo, pode implantar-se um certo "cosmopolitismo democrático", impensável nos anos 1930, quando o jornalista português pugnava à outrance por essa valia cultural que ele pretendia ver ao alcance de todos (e não só dos engenheiros à la Álvaro de Campos).

Nos nossos dias, o atravessamento do espaço é praticamente instantâneo, pelo uso de meios de comunicação electrónicos. O que se passa de facto desde a revolução das TIC é que a cibercultura representa o triunfo do artificial sobre o antigo natural, de tal modo que Mario Perniola (2005) fala no sex appeal do inorgânico para denotar a apetência contemporânea por uma vida em rede, baseada em toda a espécie de dispositivos artificiais assentes na electrónica. Estes dispositivos em rede organizam-se segundo a teoria dos grafos referida atrás (Biggs et al.,1986), em que impera o fenómeno das transições críticas de fase. De facto, em certos pontos do grafo onde se dão "transições críticas" (i.e., onde se ultrapassa um certo threshold), surge o fenómeno da emergência, que consiste na inesperada e imprevisível aparição de qualquer coisa de novo que não se pode deduzir de um qualquer modelo clássico, baseado essencialmente em relações lineares. Faz-se assim 
a ligação entre a teoria dos grafos e os sistemas dinâmicos não lineares (vulgo, teoria do caos) através de uma conceptualização não-euclidiana do espaço que abarca, em especial, um modelo viral de propagação de epidemias e outras doenças contagiosas (o qual pode ser visto como o "lado negro" - Mr. Hyde - dos cadavres exquis e robots-pintores atrás referidos, que fazem o papel do Dr. Jekyll).

\section{CONCLUSÕES}

O espaço ocupa um papel cada vez mais importante na contemporaneidade, "iluminando" algumas disciplinas para além da geografia. Mesmo naquelas soft sciences e nas artes que antes eram dominadas pelo tempo, o spatial turn que nelas se tem verificado nos nossos dias só tem valorizado o seu conteúdo formal, para além do incremento na sua produção cultural.

\section{BIBLIOGRAFIA}

Biggs, N. Lloyd, E. \& Wilson, R. (1986). Graph Theory. Oxford: Oxford University Press.

Careri, F. (2002). Walking as an aesthetic practice. Barcelona: Gustavo Gil.

Chico, A. (2014). Geografía escrita. Una introducción. Quimera - Revista de Literatura, Abril, 2014: 11-12.

Deleuze, G. \& Guattari, F. (1980). Mille Plateaux. Paris: Minuit.

Deleuze, G. \& Parnet, C. (1996). Dialogues. Paris: Flammarion.

Diego, E. (2008). Contra el mapa. Madrid: Siruela.

Gordillo, G. (2012). Les occupations en tant que nœuds de résonance. In La Découverte (Eds.) \#INDIGNÉS! D'Athènes à Wall Street, échos d'une insurrection des consciences (pp. 34- 43). Paris: Zones.

Gray, J. (1992). Ideas de Espacio. Milano: Mondadori.

Hodder, I. (ed.) (1978) The spatial organization of culture. London: Gerald Duckworth Co.

Kaplan, R. D. (2012). The Revenge of Geography. What the map tells us about coming conflicts and the battle against fate. New York: Random House.

Lefebvre, H. (1970). La révolution urbaine. Paris: Gallimard. Lefebvre, H. (2012). O direito à cidade. (Trad. Rui Lopo). Letra livre, Lisboa.
Moura, L. Pereira, H. G. (2004). Man+Robots, Symbiotic Art. France: Villeurbane, Institut d"Art Contemporain, Collection Écrits d"Artistes.

Perniola, M. (2005). O sex appeal do inorgânico. (Trad. Nilson Moulin). São Paulo: Studio Nobel.

Pickles, J. (2004). A History of Spaces: Cartographic Reason, Mapping, and the Geo-Coded World. London: Routledge.

Rosa, H. (2011). Accélération. Une critique sociale du temps. Series: «Sciences humaines et sociales», $1^{\mathrm{e}}$ édition, traduit de l'allemand par Didier Renault. Paris: La Découverte.

Santos, M. (1997). A natureza do espaço: técnica e tempo, razão e emoção. São Paulo: Hucitec.

Santos, E. (2007). A produção do espaço urbano e a imagem da cidade pelo migrante jovem. Caminhos da Geografia, 8, (24), 33-45.

Vários (1958). Internationale Situationniste 1, Paris. http://www.larevuedesressources.org/IMG/pdf/ internationale_situationniste_1.pdf

Žižek, S. (2014). Event, philosophy in transit. London: Penguin Books. 